\title{
HUBUNGAN KESEJAHTERAAN KARYAWAN DENGAN KINERJA KARYAWAN PADA HOTEL LUSY DI BANDAR LAMPUNG
}

\author{
Ari Agustina ${ }^{(1)}$, Khairul Saleh $^{(2)}$, Sodirin $^{(3)}$ \\ Fakultas Ekonomi Universitas Sang Bumi Ruwa Jurai \\ agustina.ari02@gmail.com,khairul.saleh@fe.saburai.ac.id, sodirin@fe.saburai.ac.id
}

\begin{abstract}
Abstrak. Hotel Lusy adalah salah satu hotel melati yang berlokasi di Jalan Pangeran Diponegoro No.186 Kelurahan Gulak Galik Kecamatan Teluk Betung Utara 35214 Bandar Lampung didirikan pada tahun 1986. Hotel ini memiliki 36 karyawan yang terbagi dalam beberapa departement. Permasalahan yang dihadapi adalah apakah kesejahteraan karyawan mempunyai hubungan dengan kinerja kerja karyawan pada hotel Lusy di Bandar Lampung. Tujuan penelitian ini adalah untuk mengetahui seberapa besar hubungan kesejahteraan karyawan dengan kinerja karyawan pada Hotel Lusy. Metode penelitian yang digunakan adalah analisis kualitatif dan kuantitatif menggunakan rumus korelasi product moment. Teknik data yang digunakan adalah teknik populasi dari 36 orang karyawan. Hasil perhitungan koefisien penentu sebesar 94,28\% ini menunjukkan bahwa kesejahteraan berhubungan dengan kinerja karyawan. Hasil perhitungan $t$ (test student), menunjukkan bahwa nilai $t_{\text {hitung }}$ adalah 23,68, sedangkan nilai $t_{\text {tabel }}$ adalah 1,691. Dengan demikian hipotesis yang menyatakan "Ada Hubungan Kesejahteraan Karyawan dengan Kinerja Karyawan pada Hotel Lusy Di Bandar Lampung” dapat diterima.
\end{abstract}

Kata kunci: Hotel, Karyawan, Kesejahteraan, Kinerja.

\section{PENDAHULUAN}

Sumber daya manusia merupakan aset paling penting dalam suatu organisasi serta mempertahankan dan mengembangkan organisasi dalam berbagai tuntutan masyarakat dan jaman. Kinerja sumber daya yang baik merupakan hal penting bagi kelangsungan hidup organisasi. Jika organisasi ingin berkembang dengan pesat, organisasi harus mempunyai sumber daya manusia yang mampu menampilkan kinerja yang baik.

Tuntutan bagi setiap perusahaan untuk dapat bersaing dalam pasar bebas harus berusaha dengan cara meningkatkan dengan kecakapan dan keterampilan tenaga kerja yang digunakan, sehingga diperlukan suatu perhatian dan pengelolaan khusus dan baik bagi mereka. Pengembangan karyawan adalah usaha-usaha untuk meningkatkan keterampilan maupun pengetahuan umum bagi karyawan agar pelaksanaan pencapaian tujuan lebih efisien (Ranupandoyo, 2012). Pengembangan karyawan biasanya dilakukan dengan mengikutsertakan karyawan pada program pendidikan dan pelatihan, baik yang diselenggarakan oleh perusahaan maupun instansi lain.

Dalam rangka pembinaan dan pengembangan sumber daya manusia unsur kesejahteraan perlu diperhatikan dengan sungguh-sungguh karena kesejahteraan karyawan merupakan faktor yang sangat menentukan dalam memacu semangat kinerja karyawan. Dengan meningkatnya kinerja karyawan itu dapat pula menunjang atau mempengaruhi kesejahteraan karyawan tersebut, baik secara langsung maupun tidak langsung. Secara langsung yaitu dengan naiknya gaji karyawan, pemberian tunjangan keluarga maupun bonus, sedangkan secara tidak langsung yaitu bisa dengan memberikan kesempatan promosi jabatan kepada karyawan yang berprestasi baik. 
Hotel Lusy adalah salah satu hotel di Bandar Lampung yang menggunakan sarana dan prasarana yang cukup modern, tentunya sangat memerlukan pengendalian dalam pelaksanaan kegiatan pekerjaan sesuai dengan tatanan struktur organisasi dan bekerja sama atas dasar pembagian kerja, peran dan wewenang. Jumlah seluruh karyawan Hotel Lusy adalah 30 orang. Seluruh karyawan tersebut dalam melaksanakan tugas-tugas pekerjaannya didasarkan atas pembagian kerja, peran dan wewenang yang dikendalikan oleh pimpinan. Kemampuan karyawan dalam mengaplikasikan dirinya terhadap pekerjaan sesuai dengan rencana tujuan, mempunyai peran penting dalam menentukan hotel.

Kesejahteraan karyawan sangat penting untuk mempertahankan karyawan agar tidak pindah ke perusahaan lain, meningkatkan semangat kerja dan meningkatkan sikap loyalitas karyawan terhadap perusahaan. Maka perusahaan diharapkan dapat memberikan kesejahteraan dengan baik. Dengan kesejahteraan yang dirasakan bagi karyawan, maka diharapkan produktivitas kerja karyawan lebih optimal, secara kualitas, kuantitas dan ketepatan waktu penyelesaian pekerjaan sesuai dengan permintaan konsumen.

SK UMK Bandar Lampung dengan nomor G/659/III.05/HK/2016 ditetapkan pada angka $\mathrm{Rp} 2.054 .365,32$ yang ditandatangani oleh Gubernur Lampung $M$. Ridho Ficardo pada tanggal 21 November 2016. Berdasarkan data gaji karyawan pada Hotel Lusy, menunjukkan bahwa pada tahun 2017 gaji karyawan pada Hotel Lusy masih sebagian yang berada dibawah Upah Minimum Kabupaten/Kota (UMK), maka pendapatan yang diterima oleh karyawan hotel tersebut masih belum optimal.

Menurut Malayu S.P. Hasibuan (2012), produktivitas adalah perbandingan antara output dengan input. Jika produktivitas naik, ini hanya dimungkinkan oleh adanya peningkatan efisiensi (waktu, bahan, tenaga) dan sistem kerja, teknik produksi dan adanya peningkatan kerja karyawan.

Berdasarkan beberapa hal yang sudah disebutkan, penulis tertarik melakukan penelitian lebih lanjut dengan judul: "Hubungan Kesejahteraan Karyawan Dengan Kinerja Karyawan Pada Hotel Lusy di Bandar Lampung"

\section{KAJIAN TEORI}

\section{Pengertian Kesejahteraan Karyawan}

Setiap orang yang hidup selalu menginginkan kesejahteraan hidup sebab dengan sejahtera hidupnya akan menjadi tenang dan tentram. Menurut W.J.S. Poerwodarminto (2012) kesejahteraan adalah suatu kondisi aman sentosa dan makmur terhindar dari berbagai ancaman dan kesulitan yang dirasakan seseorang yang telah melakukan suatu pekerjaan di suatu tempat atau perusahaan.

\section{Faktor-Faktor yang Mempengaruhi Kesejahteraan Karyawan}

1. Faktor kesejahteraan karyawan yang mempengaruhi hubungan antara karyawan dengan karyawan meliputi :

a) Gaji dan upah yang baik

Gaji bisa dipakai untuk kebutuhan psikologis dan sosial.

b) Rekan kerja yang kompak

Keinginan ini merupakan cermin dari kebutuhan sosial. Seorang karyawan mungkin berkeberatan untuk dipromosikan, hanya karena tidak menginginkan kehilangan rekan kerja yang kompak.

c) Kondisi kerja yang aman, nyaman dan menarik

Kondisi kerja yang aman berasal dari kebutuhan akan rasa aman disamping itu juga tempat kerja yang nyaman dan menarik. 
2. Faktor kesejahteraan karyawan yang mempengaruhi hubungan antara karyawan dengan pimpinan :

a) Pimpinan yang adil dan bijaksana.

b) Melengkapi para karyawan dengan sumber dana yang diperlukan untuk menjalankan tugasnya.

c) Mengkomunikasikan kepada karyawan tentang apa yang diharapkan dari mereka.

d) Memberikan penghargaan untuk mendorong kinerja.

\section{Pengertian Kinerja Pegawai}

Pengertian kinerja yaitu suatu hasil kerja yang dihasilkan oleh seorang karyawan diartikan untuk mencapai tujuan yang diharapkan. Menurut Anwar Prabu Mangkunegara, (2012), pengertian kinerja adalah hasil kerja secara kualitas dan kuantitas yang dicapai oleh seorang karyawan dalam melaksanakan tugasnya sesuai dengan tanggungjawab yang diberikannya. Sedangkan definisi kinerja karyawan menurut Faustino Cardoso Gomes (2013) yaitu "Performansi adalah catatan yang dihasilkan dari fungsi suatu pekerjaan tertentu atau kegiatan selama periode waktu tertentu".

Berdasarkan uraian tersebut diatas mengungkapkan bahwa dengan hasil kerja yang dicapai oleh seorang karyawan dalam melakukan suatu pekerjaan dapat dievaluasi tingkat kinerja pegawainya, maka kinerja karyawan harus dapat ditentukan dengan pencapaian target selama periode waktu yang dicapai organisasi.

\section{Pengukuran Kinerja Karyawan}

Pengukuran kinerja pada dasarnya digunakan untuk mengetahui sejauh mana tingkat efektivitas dan efisiensi kerja karyawan dalam menghasilkan suatu hasil. Pengukuran dari kinerja karyawan yang dikemukakan oleh Faustino Cardoso Gomes, (2013) sebagai berikut :

1. Quantity of work, jumlah kerja yang dilakukan dalam suatu periode yang ditentukan.

2. Quality of work, kualitas kerja yang dicapai berdasarkan syarat-syarat kesesuaian dan kesiapannya.

3. Job Knowledge, luasnya pengetahuan mengenai pekerjaan dan keterampilannya.

4. Creativeness, keaslian gagasan-gagasan yang dimunculkan dan tindakantindakan untuk menyelesaikan persoalan-persoalan yang timbul.

5. Cooperation, kesediaan untuk bekerjasama dengan orang lain atau sesame anggota organisasi.

6. Dependability, kesadaran untuk dapat dipercaya dalam hal kehadiran dan penyelesaian kerja.

7. Intiative, semangat untuk melaksanakan tugas-tugas baru dan dalam memperbesar tanggungjawabnya.

8. Personal Qualities, menyangkut kepribadian, kepemimpinan, keramah tamahan dan integritas pribadi.

Peranan manajemen sangat strategis untuk peningkatan kinerja yaitu dengan mengkombinasikan dan mendayagunakan semua sumber produksi, menetapkan fungsi-fungsi manajemen, menciptakan sumber kerja dan pembagian kerja, menempatkan orang yang tepat, serta menciptakan kondisi lingkungan kerja yang aman dan nyaman.

\section{METODE PENELITIAN}

\section{Objek Penelitian}

Objek dalam penelitian ini adalah Hotel Lusy yang berlokasi di Jln. Pangeran Diponegoro No. 186, Gulak-Galik, Teluk Betung Utara, Bandar Lampung. 
Metode dan Teknik Pengumpulan Data

Dalam penelitian ini jenis data yang diperlakukan adalah :

a. Data Primer

Data primer merupakan data dasar yang akan diperoleh langsung tanpa perantara orang atau lembaga lain sebagai pihak ketiga. Data primer ini diperoleh dengan wawancara melalui responden dengan menggunakan daftar pertanyaan.

\section{b. Data Sekunder}

Data skunder merupakan data yang diperoleh melalui orang lain yang berhubungan dengan permasalahan yang dipecahkan. Data sekunder ini diperoleh melalui cara studi dokumenter yaitu mengumpulkan dan mempelajari brosurbrosur serta dokumen organisasi.

Langkah-langkah pengumpulan data yang penulis lakukan dengan mengadakan penelitian lapangan yaitu Penelitian yang dilakukan di Hotel Lusy, adapun teknik yang digunakan dalam pengumpulan data adalah dengan :

1. Observasi, yaitu mengadakan survey atau pengamatan langsung kelokasi penelitian.

2. Interview atau wawancara, yaitu mengadakan tanya jawab langsung dengan karyawan pada Hotel Lusy.

3. Dokumentasi, yaitu mengumpulkan dan mencatat dokumentasi yang relevan.

4. Quisioner, yaitu membuat pertanyaan yang berhubungan dengan variabel penelitian.

\section{Sampel dan Populasi}

Menurut Sugiyono, (2013) apabila subjeknya $<100$, lebih baik diambil semua, tetapi bila subjeknya $>100$, dapat diambil $10 \%, 15 \%$ atau lebih. Maka teknik penelitian yang diambil menggunakan teknik populasi, mewakili seluruh karyawan Hotel Lusy yang berjumlah 36 orang.

\section{Metode Analisis Data}

Analisis kualitatif untuk menganalisis pokok permasalahan mengenai kesejahteraan dengan kinerja kerja karyawan pada Hotel Lusy melalui pendekatan teori atau manajemen sumber daya manusia berupa keterangan atau penjelasan mengenai kesejahteraan karyawan atau tingkat kinerja karyawan.

Analisis kuantitatif bertujuan untuk mengetahui seberapa besar hubungan kesejahteraan karyawan dengan kinerja karyawan pada Hotel Lusy menggunakan rumus statistik koefisiensi korelasi product moment (Sudjana, 2011):

$$
r_{x y}=\frac{N \sum X_{i} Y-\left(\sum X_{i}\right)\left(\sum Y_{i}\right)}{\sqrt{\left\{N \sum X_{i}^{2}-\left(\sum X_{i}\right)^{2}\right\}\left\{N \sum Y_{i}^{2}-\left(\sum Y_{i}\right)^{2}\right\}}}
$$

Keterangan:

$$
\begin{aligned}
& r_{x y}=\text { Koefisieni korelasi } \\
& X=\text { Variabel kesejahteraan karyawan } \\
& \mathrm{Y}=\text { Variabel kinerja karyawan } \\
& \mathrm{N}=\text { Jumlah populasi }
\end{aligned}
$$

Untuk mengetahui besarnya pengaruh, penghitungan koefisien korelasi tersebut kemudian dilanjutkan dengan Rumus Koefisien Determinasi atau Koefisien Penentu (KP):

$$
K P=(r)^{2} x 100 \%
$$

Untuk menguji secara hipotesis secara parsial digunakan Uji t dengan rumus :

$$
t_{\text {hitung }}=\frac{r \sqrt{N-2}}{\sqrt{1-r^{2}}}
$$

Keterangan:

$$
\begin{array}{ll}
\mathrm{t}_{\text {hitung }} & =\text { Nilai } \mathrm{t} \\
\mathrm{r} & =\text { Koefisien Korelasi }
\end{array}
$$




$$
\mathrm{N} \quad=\text { Jumlah responden }
$$

Kriteria untuk Uji $\mathrm{t}$ adalah sebagai berikut :

a) Jika $t_{\text {hitung }}>t_{\text {tabel }}$ maka Ha diterima dan Ho ditolak.

b) Jika $t_{\text {hitung }} \leq \mathrm{t}_{\text {tabel }}$ maka Ha ditolak dan Ho diterima.

\section{HASIL DAN PEMBAHASAN}

\section{Analisis Kualitatif}

Analisis kualitatif yang berkaitan dengan kesejahteraan dan kinerja karyawan. Hasil masing-masing 10 (sepuluh) pertanyaan kepada 36 responden, berkaitan tentang kesejahteraan karyawan (X) dan tingkat kinerja karyawan (Y). Sebelumnya akan ditentukan terlebih dahulu skor dan interval masing-masing kuesioner, adapun skor tersebut:

Jika responden menjawab A skornya 3 , B skornya 2, dan C skornya 1. Berdasarkan interval kelas tersebut, maka total skor 10-16 tergolong kurang baik/rendah, antara 17-23 tergolong cukup baik/sedang dan antara 24-30 tergolong baik/tinggi.

Hasil jawaban kuesioner 36 responden tentang kesejahteraan karyawan, terdapat : 27 responden $(75,00 \%)$ orang karyawan menyatakan bahwa kesejahteraan yang dilaksanakan oleh perusahaan tergolong baik / tinggi. 6 responden $(16,67 \%)$ orang karyawan menyatakan bahwa kesejahteraan yang dilaksanakan oleh pimpinan tergolong cukup baik / sedang, dan 3 responden $(8,33 \%)$ orang karyawan menyatakan bahwa kesejahteraan yang dilaksanakan oleh perusahaan tergolong kurang baik /rendah.

Selanjutnya hasil jawaban kuesioner yang berkaitan dengan tingkat kinerja karyawan diperoleh hasil : 30 responden $(83,33 \%)$ orang karyawan menyatakan bahwa kinerja karyawan tergolong baik/ tinggi. 2 responden $(5,56 \%)$ orang karyawan menyatakan bahwa kinerja karyawan tergolong cukup baik/sedang, dan 4 responden $(11,11 \%)$ orang karyawan menyatakan bahwa kinerja karyawan tergolong kurang baik/ rendah, seperti yang ditunjukkan pada Tabel 1.

Tabel 1. Hasil rekapitulasi kuesioner kepada 36 responden pada Hotel Lusy.

\begin{tabular}{cccc}
\hline \multirow{2}{*}{ KETERANGAN } & \multicolumn{3}{c}{ KRITERIA } \\
\cline { 2 - 4 } & Baik & Sedang & $\begin{array}{c}\text { Kurang } \\
\text { Baik }\end{array}$ \\
\hline $\begin{array}{c}\text { Kesejahteraan } \\
\text { Karyawan }\end{array}$ & $(75,00 \%)$ & $(16,67 \%)$ & $(8,33 \%)$ \\
Kinerja & 30 & 27 & 4 \\
Karyawan & & & \\
& $(83,33 \%)$ & $(5,56 \%)$ & $(11,11 \%)$ \\
& & & \\
\hline
\end{tabular}

Berdasarkan hasil kuesioner tersebut di atas, sebagian besar karyawan menyatakan bahwa kesejahteraan karyawan tergolong baik, sedangkan kinerja karyawan sebagian besar juga menyatakan baik, maka dapat diartikan bahwa: "Ada Hubungan Positif Kesejahteraan Karyawan Dengan Kinerja Karyawan Pada Hotel Lusy Di Bandar Lampung”.

\section{Analisis Kuantitatif}

Setelah dianalisis menggunakan analisis kualitatif, maka selanjutnya dianalisis dengan menggunakan analisis kuantitatif. Data kuantitatif ini diperoleh dari mentabulasikan hasil kuesioner yabg disebarkan kepada 36 responden dalam bentuk angka-angka sesuai dengan skor jawaban yang telah dijelaskan sebelumnya.

Analisis kuantitatif dimaksudkan untuk menganalisis data mengunakan perhitungan-perhitungan statistic korelasi Product Moment untuk mengetahui seberapa besar hubungan kesejahteraan 
karyawan (X) dengan tingkat kinerja karyawan (Y) pada Hotel Lusy di Bandar Lampung. Berdasarkan rekapitulasi hasil kuesioner diperoleh :
$\mathrm{N}=36$
$\sum X^{2}=22.772$
$\sum X=885$
$\sum \mathrm{Y}^{2}=23.224$
$\sum \mathrm{Y}=895$
$\sum X Y=22.968$

Selanjutnya angka-angka tersebut dimasukkan dalam rumus korelasi product moment. Berdasarkan hasil perhitungan, nilai $\mathrm{r}$ hitung adalah 0,971 , kemudian nilai tersebut dibandingkan dengan nilai $\mathrm{r}$ tabel product moment, taraf signifikan 5\% adalah 0,329 dan taraf signifikan $1 \%$ adalah 0,424. Maka hasil perbandingan $r$ hitung dengan $r$ tabel menunjukan bahwa nilai $\mathrm{r}$ hitung 0,971 $>\mathrm{r}$ tabel 0,329 dan 0,424. $\mathrm{r}$ hitung 0,971 apabila diukur menggunakan pengukuran korelasi, terletak diantara 0,71-1,00 dengan kriteria baik/ tinggi.

Menurut Sudjana, (2011) untuk mengetahui keeratan hubungan antara variabel menggunakan perhitungan kadar persentase koefisiensi penentu, maka hubungan kesejahteraan dengan tingkat kinerja karyawan pada Hotel Lusy di Bandar Lampung adalah $\mathrm{KP}=94,28 \%$. Hasil perhitungan koefisiensi penentu tersebut menunjukkan bahwa kadar persentase hubungan kesejahteraan dengan tingkat kinerja karyawan adalah 94,28\% dan sisanya sebesar $5,72 \%$ ada berhubungan dengan faktor lainnya.

Hasil perhitungan $t$ test student di atas, menunjukkan bahwa nilai $t$ hitung adalah 23,68 pada $\mathrm{N}=36$, sedangkan nilai $t$ tabel dengan menggunakan derajat kebebasan (db) $95 \%(\alpha=5 \%)$ dan (N - 2). Maka perbandingannya adalah $\mathrm{t}$ hitung 23,68 $>\mathrm{t}$ tabel 1,691. Dengan demikian dapat disimpulkan bahwa, hipotesis yaitu: "Ada Hubungan Kesejahteraan Karyawan Dengan Kinerja Karyawan Pada Hotel Lusy Di Bandar Lampung", dapat diterima.

\section{KESIMPULAN DAN SARAN}

\section{Kesimpulan}

Berdasarkan hasil penelitian dapat disimpulkan bahwa diketahui $\mathrm{r}$ hitung = 0,971, maka setelah dibandingkan dengan nilai $\mathrm{r}$ tabel korelasi product moment pada $\mathrm{N}$ $=36$ pada taraf signifikan $5 \%=0,329$ maupun pada taraf signifikan $1 \%=0,424$, perbandingan tersebut menunjukkan bahwa $\mathrm{r}$ hitung $0,971>\mathrm{r}$ tabel : 0,329 dan 0,424, dimana $r$ hitung 0,971 berdasarkan pada korelasi baik / tinggi. Hasil perhitungan koefisien penentu sebesar 94,28\% ini menunjukkan bahwa kesejahteraan karyawan pada Hotel Lusy di Bandar Lampung berhubungan dengan kinerja karyawan, sedangkan sisanya 5,72\% berhubungan dengan faktor lainnya. Hasil t hitung adalah $=23,68$ pada $N=36$. Setelah nilai tersebut dibandingkan dengan nilai $\mathrm{t}$ tabel dengan menggunakan derajat kebebasan (db) 95\% ( $\alpha=5 \%)$ diperoleh hasil $\mathrm{t}$ hitung lebih besar daripada $\mathrm{t}$ tabel yaitu : $\mathrm{t}$ hitung $=23,68>\mathrm{t} 0,05(\mathrm{~N}-2)=$ 1,691. Dengan demikian dapat disimpulkan bahwa hipotesis yang sebelumnya diajukan, yaitu: "Ada Hubungan Kesejahteraan Karyawan Dengan Kinerja Karyawan Pada Hotel Lusy di Bandar Lampung", dapat diterima.

\section{Saran}

Adapun saran yang diajukan peneliti adalah sebagai berikut:

1. Variabel tunjangan kesejahteraan berpengaruh signifikan terhadap kinerja karyawan, oleh karena itu pihak hotel sebaiknya memperhatikan faktor tersebut agar kinerja karyawan semakin meningkat.

2. Dengan memperhatikan dan melaksanakan kesejahteraan karyawan dengan baik, maka karyawan akan bekerja dengan efektifitas, sehingga 
kualitas, kuantitas dan waktu penyelesaian pekerjaannya dapat sesuai dengan yang direncanakan.

\section{DAFTAR PUSTAKA}

Arikunto, Suharsimi. 2006. Prosedur Penelitian Suatu Pendekatan Praktek. Jakarta: Renika Cipta.

As'ad, Moh. 2012. Seri Ilmu Sumber Daya Manusia - Psikologi Industri. Yogyakarta: BPFE.

Gomes, Faustino $\quad$ Cardoso. 2013. Manajemen Sumber Daya Manusia, cetakan keenam. Yogyakarta: Penerbit Andi.

Handoko, T. Hani. 2013, Manajemen Edisi 2. Yogyakarta: BPFE.

Hasibuan, Malayu S.P. 2012. Manajemen Sumber Daya Manusia. Jakarta:

CV. Haji Masagung.

Hasibuan, Malayu S.P. 2012. Manajemen Sumber Daya Manusia. Edisi revisi. Jakarta: PT. Gunung Agung.

Mangkunegara, Anwar Prabu. 2012. Manajemen Sumber Daya Manusia Perusahaan. Bandung: PT.Remaja.

Moekijat. 2012. Manajemen Sumber Daya Manusia. Bandung: Mandar Maju.

Poerwodarminto, W.J.S. 2012. Kamus Umum Bahasa Indonesia. Jakarta: PN Balai Pustaka.

Ranupandoyo, Heidjrahman. 2012. Manajemen Personalia. Jakarta: Raja Grafindo Persada.

Saifudin, Azwar. 2007. Metode Penelitian. Yogyakarta.
Saydam. 2011. Statistik Induktif Untuk Ekonomi Dan Bisnis.Yogyakarta: UPP AMP YKPN.

Sudjana. 2011. Metode Statistik. Bandung: Sinar Baru.

Sugiyono. 2013. Pengantar Metode Statistika. Cetakan ke-5. Jakarta: LP3ES. 